\title{
The Response Characteristics of Xilingol Grassland to Uneven Distribution of Precipitation at Temporal and Spatial Scale
}

\author{
Qiaofeng Zhang ${ }^{1,2,3,4}$, Hongbo Yu ${ }^{1,3}$, Guixiang Liu' ${ }^{2}$, Yuhai Bao ${ }^{1,3}$ \\ ${ }^{I}$ College of Geographical Science, Inner Mongolia Normal University, Hohhot 010022, China \\ ${ }^{2}$ Institute of Grassland Research of Chinese Academy of Agricultural Sciences, Hohhot 010022, China \\ ${ }^{3}$ Inner Mongolia Key Laboratory of Remote Sensing and Geography Information System, Hohhot 010022, \\ China \\ ${ }^{4}$ Inner Mongolia Laboratory of Disaster Prevention and Reduction and Ecological Safety Monitoring, \\ Hohhot 010022, China
}

Received 26 September 2016

Accepted 11 October 2016

\begin{abstract}
Precipitation is the most important source of water supply, which has important significance on the vegetation growth, also is an important factor affecting the drought severity in Xilingol grassland. Based on the precipitation of 15 weather stations and MODIS MOD13A3 NDVI data, Pearson correlation analysis was used to analysis the response characteristics of NDVI to precipitation at spatial and temporal scale. Results showed that from one month view, vegetation growth was the highest correlation with the precipitation of this month from May to July, but August and September were the highest correlation with the precipitation in July. Accumulated month view, the accumulated precipitation in the last three months was very important to the vegetation growth, and snowfall in the winter of previous year played an important role in May of next year. Spatially, from one month view, Erenhot and Sonid Youqi (desert steppe region) were the highest correlation with the precipitation in two months before, the others were the highest correlation with the precipitation in one month before. Accumulated month view, Erenhot and Sonid Youqi were the highest correlation with the accumulated precipitation in the last four months, the others were the highest correlation with the accumulated precipitation in the last three months.
\end{abstract}

Keywords: Precipitation, NDVI, Spatial and temporal distribution, Correlation.

\section{锡林郭勒草原对降水量时空分配不均的响应特征}

\author{
张巧风 ${ }^{1,2,3,4}$, 于红博 ${ }^{1,3}$, 刘桂香 ${ }^{2}$, 包玉海 ${ }^{1,3}$ \\ 1.内蒙古师范大学地理科学学院, 内蒙古 呼和浩特 010022 \\ 2.中国农业科学院草原研究所, 内蒙古 呼和浩特 010010 \\ 3.内蒙古自治区遥感与地理信息系统重点实验室, 内蒙古 呼和浩特, 010022 \\ 4.内蒙古防灾减灾与生态安全监测实验室, 内蒙古 呼和浩特, 010022
}

\begin{abstract}
摘要: 降水是锡林郭勒草原最重要的水分补给源, 对草原植被的生长具有重要意义, 也是影响该区干旱程度的重 要因子。本文基于 15 个气象站点的降水量数据和 MODIS MOD13A3 NDVI 数据, 应用 Pearson 相关分析法分析 NDVI 对降水量的时空响应特征。结果表明, 单月来看, 5 7 月的 NDVI 均与当月的降水量相关性最高, 而 $8 、 9$ 月的 NDVI 均与 7 月降水量相关性最高; 累月来看, 近 3 个月的累加降水量对植被长势至关重要, 前一年冬季的 降雪量对第二年 5 月植被的返青具有重要意义。空间上, 单月来看锡林郭勒草原西部的二连浩特市和苏尼特右旗 (荒漠草原区) 与前 2 个月的降水量相关性最高, 其余均与前 1 个月的降水量相关性最高; 累月来看, 二连浩特 市和苏尼特右旗与近 4 个月的累加降水量相关性最高, 其余均与近 3 个月的累加降水量相关性最高。
\end{abstract}

关键词：降水量; NDVI; 时空分布; 相关性

Published by Atlantis Press

Copyright: the authors 


\section{1. 引言}

植被是土壤和大气之间物质和能量交换的 关键环节，在地球表面的能量交换和水分循环过 程中起着重要的作用。植被变化与气候变化相互 作用, 水热条件是决定植被变化的主要非生物因 素, 植被变化对气候变化的响应具有明显的动态 和演变特点 ${ }^{[1-3]}$ 。在全球气候变暖的大背景下, 锡 林郭勒草原的气温呈明显上升趋势 ${ }^{[4-9]}$, 年降水量 呈下降趋势 $[7,10,11]$, 气候趋于暖干化 ${ }^{[10,12-14]}$, 年 度及草原植被的主要生长季夏季的干旱程度增 加 ${ }^{[15]}$ 。锡林郭勒草原是干旱半干旱温带草原的典 型区, 草原面积较大, 草地类型多样, 饲用植物 资源丰富, 是我国北方地区重要的生态屏障和畜 牧业生产基地。 20 世纪 50 年代以来, 由于气候 变化和人类活动的影响导致草地退化严重 ${ }^{[16,17]}$, 锡林郭勒草原的生态环境变化及对气候变化的 响应一直是众多专家学者关注和研究的热点 ${ }^{[18,}$ 19]。常用的遥感数据源归一化植被指数（NDVI） 是反映植被长势的重要参数之一, NDVI 值越大 植被长势越好植被覆盖度越高, 研究表明 NDVI 主要受降水量影响, 二者正相关系数高达 0.83 以 上, 降水作为锡林郭勒草原的主要水分补给源对 植被的生长至关重要 ${ }^{[20]}$ 。

为分析降水量的月分配差异对植被长势的 影响, 本文利用近 15 年生长季 5 9 月的 NDVI 和当年该月之前的各月降水量、前一年冬季的降 雪量( $10 \sim 12$ 月) 以及累加降水量做了相关分析; 为分析降水量的空间分布差异对生长季 5 9 月植 被长势的影响, 利用各年生长季 5 9 月的 NDVI 和各气象站点的单月和累月降水量做了相关分 析。

\section{2. 研究区概况及数据与方法}

\section{1 研究区概况}

锡林郭勒草原位于中国北方内蒙自治区中 部的锡林郭勒盟, $111^{\circ} 09^{\prime} \sim 120^{\circ} 01^{\prime} \mathrm{E}, 41^{\circ} 35^{\prime} \sim$ $46^{\circ} 46^{\prime} \mathrm{N}$, 属中温带干旱、半干旱大陆性气候,
基本气候特征是寒冷、风大、雨少, 对草原畜牧 业危害严重的主要气象灾害有干旱、白灾、黑灾, 风蚀、冰雨和霜冻等; 年均降水量在 $200 \sim 350 \mathrm{~mm}$ 之间, 地区分布不均, 西北部不足 $150 \mathrm{~mm}$, 东部、 南部边缘地区可达 $400 \mathrm{~mm}$ 左右; 年内分布不均, 6 8 月的降水量占年降水量的 $70 \%$ 左右, 因此区 域性和阶段性干旱现象频繁发生; 大部分地区年 均气温在 $0 \sim 3^{\circ} \mathrm{C}$ 之间, 是我国华北最冷地区之一; 年均风速普遍在 $3.5 \sim 4 \mathrm{~m} / \mathrm{s}$, 大部地区最大风速 达 $24 \sim 28 \mathrm{~m} / \mathrm{s}$, 局部地区达 $34 \mathrm{~m} / \mathrm{s}$; 大部分地区 年日照时数在 $2800 \mathrm{~h}$ 以上, 西部和南部地区可达 $3000 \mathrm{~h}$ 以上, 年总辐射量自东向西递增。锡林郭 勒草原是欧亚大陆草原区亚洲中部亚区的组成 部分, 是内蒙古的主要草原区之一, 地带性草原 类型自东向西主要为草甸草原、典型草原、荒漠 草原，以及半隐域性的沙地植被（图 1)。

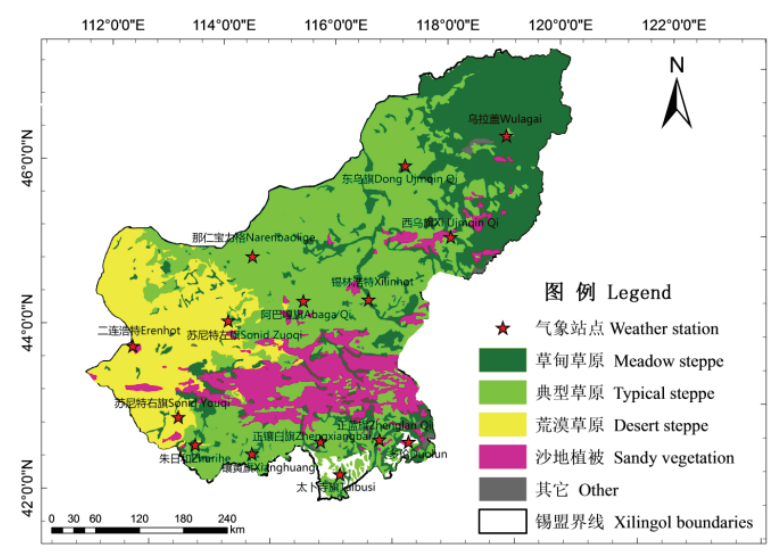

图 1. 研究区植被和气象站点

Fig.1 Vegetation zone and weather station in the study area

\section{2 数据与方法}

\subsection{1 分析数据}

气象数据来源于中国气象科学数据共享服 务网和内蒙古自治区气象局, 锡林郭勒草原 15 个气象站点（图 1）1999 2014 年月尺度的降水 量数据; 遥感数据来源于美国航空航天局 (NASA) 的 MODIS MOD13A3 2000 2014 年月尺度数据 产品, 空间分辨率为 $1 \mathrm{Km}$ 。 
为分析植被长势对降水量月分配差异的响 应特征, 利用锡林郭勒草原 15 个气象站点, 分 别提取 2000 2014 年每年生长季 5 9 月站点周围 $3 \times 3$ 像元的平均植被指数值, 形成 $5 \sim 9$ 月 225 $(15 \times 15 \times 1)$ 个 NDVI 数据样本, 对应 15 个气象 站点 1999 2014 年月降水量数据, 形成 NDVI 与 各时间尺度的降水量之间的分析数据集, 分析锡 林郭勒草原 5 9 月的 NDVI 与当年该月之前的各 月降水量、前一年冬季的降雪量（10 12 月）以 及累加降水量的相关性。

为分析植被长势对降水量空间分布差异的 响应特征, 利用锡林郭勒草原 15 个气象站点, 分别提取 2000 2014 年每年生长季 5 9 月站点周 围 $3 \times 3$ 像元的平均植被指数值, 形成各站 75 (1 站 $\times 15$ 年 $\times 5$ 个月) 个以及整个锡林郭勒草原 1125 (15 站 $\times 15$ 年 $\times 5$ 个月) 个 NDVI 数据样本序列, 对应 15 个气象站点 1999 2014 年月降水量数据, 形成 NDVI 与各气象站点的降水量之间的分析数 据集, 分析各年生长季 5 9 月的 NDVI 和气象站 点的单月和累月降水量的相关性。

降水和气温是影响植被生长的重要因子, 本 文目的是为了解自然生长状态下, 即在水热的共 同影响下, 降水时空差异对植被长势的影响, 因 此没有采用剔除温度影响的偏相关分析, 而采用 简单相关分析。

\subsubsection{Pearson 相关分析}

相关分析用于研究随机变量之间的关系密 切程度, Pearson 相关分析的简单相关系数 $r$ 的计 算见公式 (1):

$$
r=\frac{\sum(x-\bar{x})(y-\bar{y})}{\sqrt{\sum(x-\bar{x})^{2} \cdot \sum(y-\bar{y})^{2}}}
$$

公式 (1) 中, 相关系数 $r$ 是相关性大小和正负的 度量, 相关系数无量纲, 取值区间为 $[-1,1] ; r<0$ 为负相关, $r=0$ 为不相关, $r>0$ 为正相关; 相关 程度由相关系数的大小决定, 一般情况下, 相关 系数 $0<|r|<0.4$ 为低度相关, 相关系数 $0.4 \leq|r|<0.7$ 为中度相关, 相关系数 $0.7 \leq|r| \leq 1$ 为高度相关。由于多年相同月份的降水量、多年 不同月份的降水量及 NDVI 数据序列均不服从正 态分布, 因此首先对数据进行标准差标准化处理, 再采用 Pearson 相关分析。

\section{3. 结果与分析}

\section{1 植被对降水量月分配差异的响应}

各月来看 (表 1)， 5 月 NDVI 与 5 月、 4 月 和前一年 10 月的降水量均为中度相关, 相关系 数分别为 $0.45 、 0.42 、 0.42 ; 5$ 月 NDVI 与当月降 水量的相关系数最高, 与 3 月、 2 月、 1 月、 12 月和 11 月各月降水量的相关性均较低。6 月 NDVI 与 6 月、 4 月及前一年 10 月降水量的相关 性较高, 相关系数分别为 $0.47 、 0.45$ 和 0.43 , 与 其余月份降水量的相关性均较低。7 月 NDVI 与 7 月和 6 月的降水量相关性较高, 分别为 0.50 和 0.49 , 均为中度相关; 7 月 NDVI 与当月降水量 的相关系数最高, 与 3 月、 2 月、 1 月、 12 月和 11 月降水量的相关性均较低。8 月 NDVI 与 7 月 和 6 月降水量的相关性较高, 相关系数分别为 0.50 和 $0.44 ; 8$ 月 NDVI 与 7 月降水量的相关系 数最高, 与其余月份的降水量相关性均较低。9 月 NDVI 与 8 月和 7 月降水量的相关性较高, 相 关系数分别为 0.42 和 $0.44 ; 9$ 月 NDVI 与 7 月降 水量的相关系数最高, 与其余月份降水量的相关 性均较低。 
Q.F. Zhang / The Response Characteristics of Xilingol Grassland

表 1. NDVI（5 9 月）与各月降水量的 Pearson 相关系数

Table1 Correlation coefficient between NDVI from May to September and precipitation of each month

\begin{tabular}{|c|c|c|c|c|c|c|}
\hline \multirow{2}{*}{\multicolumn{2}{|c|}{$\begin{array}{c}\text { Pearson } \\
\text { 相关系数 }\end{array}$}} & \multicolumn{4}{|c|}{ NDVI } & \multirow[b]{2}{*}{9 月 } \\
\hline & & \multirow[t]{2}{*}{5 月 } & \multirow[t]{2}{*}{6 月 } & \multirow[t]{2}{*}{ 7月 } & \multirow[t]{2}{*}{8 月 } & \\
\hline & 9 月 & & & & & 0.36578 \\
\hline & 8 月 & & & & 0.3649 & 0.42381 \\
\hline & 7 月 & & & 0.49606 & 0.49619 & 0.43705 \\
\hline & 6 月 & & 0.46948 & 0.48685 & 0.4419 & 0.39962 \\
\hline 降 & 5 月 & 0.45178 & 0.36983 & 0.30096 & 0.24274 & 0.23455 \\
\hline 水 & 4月 & 0.41644 & 0.45427 & 0.38186 & 0.35761 & 0.35163 \\
\hline 量 & 3 月 & 0.19392 & 0.23587 & 0.21549 & 0.26482 & 0.24823 \\
\hline & 2 月 & 0.24098 & 0.21147 & 0.22335 & 0.22501 & 0.19188 \\
\hline & 1 月 & 0.15233 & 0.14655 & 0.16068 & 0.14788 & 0.14105 \\
\hline & 12 月 & 0.21159 & 0.26173 & 0.28769 & 0.22474 & 0.19806 \\
\hline & 11 月 & $0.09282(P=0.1653)$ & 0.19627 & 0.15535 & 0.15441 & 0.1512 \\
\hline & 10 月 & 0.42484 & 0.42556 & 0.38521 & 0.35878 & 0.34042 \\
\hline
\end{tabular}

注: 未标明 $P$ 值的相关系数均通过了 $P<0.05$ 的显著性检验。

累月来看 (图 2), 随着近 3 个月内降水量的 累加, 6 9 月的植被指数与累加降水量的相关性 明显上升，其相关系数分别为 $0.66 、 0.64 、 0.64$ 和 0.62 , 随后降水量的累加作用对植被长势的影 响与近 3 个月基本持平; 5 月的植被指数与前一 年 10 月以来累加降水量相关性最高为 0.65 , 明

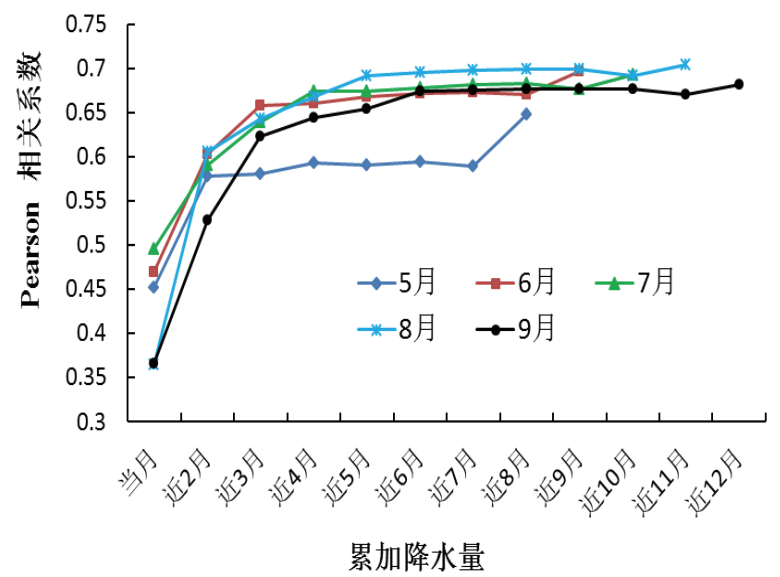

图 2. 各月 NDVI 与累月降水量的相关系数

Fig.2 Pearson correlation coefficient between monthly NDVI and cumulative precipitation
显高于与近 3 个月降水量的相关性 $0.58,5$ 月是 锡林郭勒草原的主要返青期, 说明前一年冬季的 降雪量对第二年植被的返青具有重要作用。

总体来看, 单月相关分析表明, 5 月、6 月 和 7 月锡林郭勒草原逐渐由返青到盛草状态，需 水量较大, 当月的降水量对植被的影响最大, 相 关性最高; 8 月和 9 月锡林郭勒草原逐渐由盛草 到枯黄状态，其植被指数均与 7 月的降水量相关 性最高, 说明 7 月的降水对 7 月、 8 月和 9 月的 植被长势至关重要。4 10 月的降水量与植被指数 的相关性均较高，而 3 月、 2 月、 1 月、 12 月和 11 月各月的降水量与标准植被指数的相关性均 较低; 其原因可能是 4 10 月的降水量较大, 对 年降水量的贡献较大, 导致对生长季的植被长势 影响较大, 而 11 3 月的降水量均较小, 对年降 水量的贡献较小, 因此对生长季的植被长势影响 较小。

累月相关性表明, 随着降水量的累加, 相关 性逐渐增加, 6 9 月的植被指数随着近 3 个月内 
降水量的累加, 相关性明显上升, 随后基本维持 在近 3 个月的相关性水平; 5 月的植被指数与前 一年 10 月以来累加降水量相关性明显高于近 3 个月的相关性, 5 月是锡林郭勒草原的主要返青 期, 说明前一年冬季的降雪量对第二年植被的返 青具有重要作用。由以上分析可知, 降水量的时 间分布对植被的生长至关重要, 相同的年降水量 植被的长势不一定相同，对 5 9 月锡林郭勒草原 主要生长季而言, 当年 4 7 月的降水量对该年植 被长势的影响更加重要, 前一年冬季的降雪量对 第二年 5 月植被的返青具有重要意义。

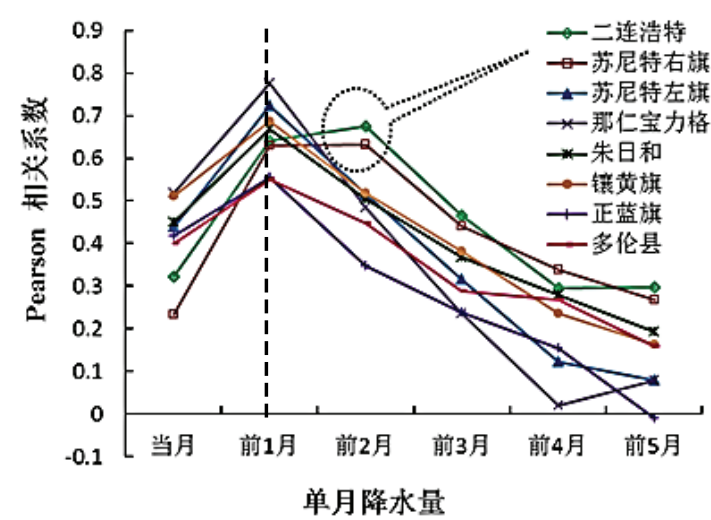

\section{2 植被对降水量空间分配差异的响应}

生长季 5 9 月的 NDVI 与单月降水量的相关 性变化曲线 (图 3) 表明, 各站点的变化趋势相 近, 均呈上升-下降的变化趋势, 相关系数在前 1 2 个月达到最大值, 随后相关性逐渐降低, 在 前 5 个月左右相关系数接近 0 值、即接近不相关。 锡林郭勒草原西部的二连浩特市和苏尼特右旗 (荒漠草原区) 对降水量的响应延滞时间为 2 个 月, 其余站点对降水量的响应延滞时间均为 1 个 月。因此相同降水量因月份和空间分布不同对植 被长势的影响不同。

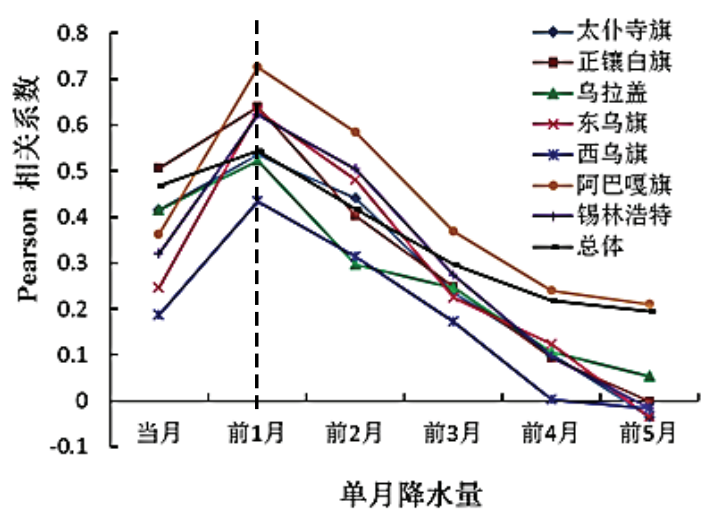

图 3. 生长季平均 NDVI 与各月降水量的相关系数

Fig.3 Correlation coefficient between mean NDVI of growing season and monthly precipitation

生长季 5 9 月的 NDVI 与累月降水量的相关 系数变化曲线（图 4) 表明, 生长季 NDVI 与各 时间尺度的累加降水量的相关系数均大于 0 , 各 站变化趋势相近, 均呈上升-稳定-下降的变化趋 势。锡林郭勒草原西部的二连浩特市和苏尼特右 旗（荒漠草原区）的植被长势与近 4 个月累加降 水量的相关性最大; 其余站点均与近 3 个月累加 降水量的相关性最大; 随后相关性呈基本稳定状 态; 在前 8 个月以上相关性明显下降, 是由于前 8 个月以上的累加降水量包括了上一年的植被生 长季, 由于当年植被长势的需水量导致了降水量 对下一年的作用减弱, 因此相关性下降。
总体来看, 锡林郭勒草原植被对单月降水量 的空间响应特征不同, 西部二连浩特市、和苏尼 特右旗（荒漠草原区）与前 2 月的降水量相关性 最高, 其余均与前 1 月的降水量相关性最高。累 月降水来看, 二连浩特市、和苏尼特右旗 (荒漠 草原）与近 4 个月的累加降水量相关性最高, 其 余均与近 3 个月的累加降水量相关性最高。说明 西部荒漠草原对降水响应较慢, 而中东部的典型 草原和草甸草原区对降水响应较快。 


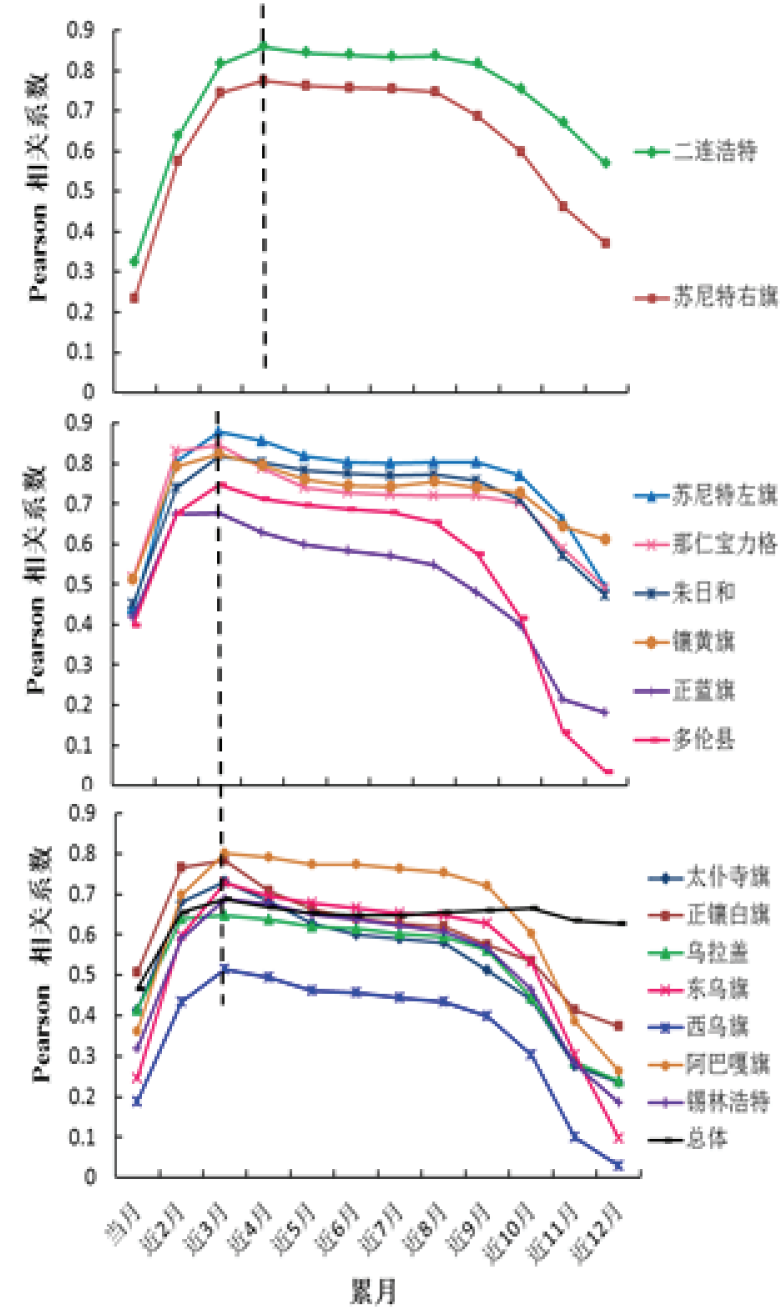

图 4. 生长季植被指数与累月降水量的相关系数

Fig.4 Pearson correlation coefficient between NDVI of growing seasonand cumulative precipitation

\section{4. 结论}

由以上分析可知:

（1）植被对降水量月分配差异的响应可知, 单月降水来看，5 7 月的植被长势均与当月的降 水量相关性最高，而 8 9 月的植被长势均与 7 月 的降水量相关性最高; 累月降水来看, 近 3 个月 的累加降水量对植被长势至关重要, 前一年冬季 的降雪量对第二年 5 月草原植被的返青具有重要 作用。

（2）植被对降水量空间分配差异的响应可 知, 单月降水来看, 锡林郭勒草原西部的二连浩 特市和苏尼特右旗（荒漠草原区）对降水量的响 应延滞时间为 2 个月, 其余站点对降水量的响应
延滞时间均为 1 个月; 累月降水来看, 二连浩特 市和苏尼特右旗与近 4 个月的累加降水量相关性 最高, 其余均与近 3 个月的累加降水量相关性最 高。说明西部荒漠草原对降水响应较慢, 而中东 部的典型草原和草甸草原区对降水响应较快, 降 水量作为该区干旱监测的重要影响因子, 其时空 尺度的选择至关重要。

\section{致谢}

本研究得到国家科技支撑计划项目 （2013BAK05B01）和中国农业科学院创新工程 “草原非生物灾害防灾减灾团队” (CAAS-ASTIP-IGR2015-04) 的资助。通讯作者: 刘桂香, Email: liugx804@163.com.

\section{参考文献}

[1] 陈效述, 喻蓉. 1982 1999 年我国东部暖温带植被 生长季节的时空变化. 地理学报. 2007, 62(1): 41-51.

[2] 朴世龙, 方精云. 1982-1999年我国陆地植被活动对 气候变化响应的季节差异. 地理学报. 2003, 58(1): 119-125.

[3] Chen X, Hu B. Spatial and temporal variation of phenological growing season and climate change impacts in temperate eastern China. Global Change Biology. 2005, 11(7): 1118-1130.

[4] 王学强, 董春艳, 杜爱萍, 等. 1961-2009年锡林 郭勒盟气温突变特征分析. 内蒙古气象. 2011(01): 22-24.

[5] 董春艳, 白海云, 何东升, 等. 1961-2010年锡林 郭勒盟极端气温事件变化分析.内蒙古气象. 2012(03): 7-9.

[6] 张捷凤. 1961-2010年锡林郭勒盟气候变化特征研 究. 北京农业. 2015(03): 135-136.

[7] 包姝芬, 马志宪, 崔学明. 近 50 年锡林郭勒盟的气 候变化特征分析. 内蒙古农业大学学报(自然科学 版). 2011(03): 157-160.

[8] 黄凤茹, 贺俊杰, 乌莉莎, 等. 近半个世纪来锡林 郭勒盟地区气温变化特征分析. 干旱区资源与环 境. 2011(10): 126-130.

[9] 王海梅, 李政海, 乌兰, 等. 锡林郭勒草原区气温 的时空变化特征. 生态学报. 2011，31(24): 7511-7515.

[10] 曹立国, 刘普幸, 张克新, 等. 锡林郭勒盟草地 对气候变化的响应及其空间差异分析. 干旱区研 究. 2011(05): 789-794. 
[11] 王海梅, 李政海, 韩经纬. 锡林郭勒草原区降水 量的时空变化规律分析. 干旱区资源与环境. 2012(06): 24-27.

[12] 王海梅, 李政海, 阎军, 等. 锡林郭勒草原不同 生态地理区降水周期变化特征的小波分析. 水土 保持通报. 2010(05): 46-49.

[13] 陈金, 李政海, 贾树海, 等. 锡林郭勒草原区气 候干旱化的时空变化规律. 内蒙古大学学报(自然 科学版). 2011(03): 304-310.

[14] 王海梅, 李政海, 韩国栋, 等. 锡林郭勒盟气候 干燥度的时空变化规律. 生态学报. 2010(23): 6538-6545.

[15] 张巧风, 刘桂香, 于红博, 等. 基于标准化降水 指数的锡林郭勒盟干旱特征分析. 自然灾害学报. 2015(05): 119-128.
[16] 缪丽娟, 蒋冲, 何斌, 等. 近10a来蒙古高原植被 覆盖变化对气候的响应. 生态学报. 2014(05): 1-9.

[17] 曹金鍀, 喜智慧, 陈晋, 等. 基于遥感的草原退化 人为因素影响趋势分析. 植物生态学报. 2006(02): 268-277.

[18] 王海梅. 锡林郭勒地区气候变化规律与植被覆盖 变化驱动机制研究. 内蒙古农业大学, 2009.

[19] 曹立国, 刘普幸, 张克新, 等. 锡林郭勒盟草地 对气候变化的响应及其空间差异分析. 干旱区研 究. 2011(05): 789-794.

[20] 杭玉玲, 包刚, 包玉海, 等. 2000-2010年锡林郭 勒草原植被覆盖时空变化格局及其气候响应. 草 地学报. 2014(06): 1194-1204. 